\title{
EXPLORING THE SHOPPING MOTIVATIONS OF INTERNATIONAL RESIDENTIAL TOURISTS
}

\author{
MARÍA D. DE JUAN-VIGARAY* AND JOAN B. GARAU-VADELL†
}

*Marketing Department, Faculty of Business and Economics, Universidad de Alicante, Alicante, Spain $\dagger$ Business Department, Faculty of Business Administration, Universitat de les Illes Balears, Palma, Spain

Over the last few decades, so-called "international residential tourism" has increased considerably, creating a new consumer base in tourist destinations, particularly in southern Europe, whose shopping motivations are unknown. As a rule, existing literature has focused its attention on studying consumer motivations in their places of residence, references to the study of the international residential tourist's (IRT's) shopping motivations being very limited. It is in this context that this study examines the main contributions related to IRT shopping motivations. Taking as a starting point empirical research carried out in two top international tourist destinations, the study analyzes and contrasts the applicability of general theoretical contributions to this specific IRT segment. The results obtained confirm the existence, although not without its variations, of certain stability in the main aspects relating to shopping motivation, allowing the foundations to be laid for the incorporation of shopping motivation as a variable for the segmentation of IRTs. Both for tourist resort managers and retailers in the area, having access to a valid scale for measuring these motivations may be of great help to them in being able to categorize IRTs in accordance with their shopping motivations. In this way, they will have a broader knowledge of the market and how it is made up and it will facilitate the implementation of marketing policies aimed at improving the planning of commercial areas, as well as help them to adapt their product range and communication to the segments that are of most interest to their companies and destinations.

Key words: Residential tourism; Tourist destinations; International residential tourists (IRTs); Shopping motives; Shopping motivation scale

Introduction

The appearance and consolidation of new market segments (Laesser \& Zehrer, 2012) is leading to an acceleration in change processes in society in general and particularly in the traditional tourism industry, brought about by transformations in the international environment, tourist preferences, and their behavior (Alegre \& Cladera, 2006; Hawkes \& Kwortnik, 2006). The ageing population, an increase 
in disposable income in some countries, new consumer lifestyles, new ways of organizing leisure and work time, the possibility to invest in property abroad, and the appearance of low-cost airlines, among other factors, have led many people to buy and/or rent homes in other countries to spend long stretches of time in areas with a better climate than their place of origin (Kaftanoglu \& Timothy, 2013), favoring so-called residential tourism.

This form of tourism also has a lot in common with migration (O'Reilly, 2007), it being possible to differentiate between two types of residential tourism: national residential tourism and international residential tourism. National residential tourism involves citizens of the country in question and does not present a relevant migratory aspect. International residential tourism, however, consists of foreign citizens spending extended periods of time in the host country, enjoying the pleasant climate and becoming integrated into the life offered by the new destination. In contrast, this type of tourism does present a temporary migratory aspect. The uniqueness of this current study is precisely the combination of special tourists and singular emigrants with different travel motivations that emerge in the industry and that need to be studied in depth.

This research focuses on the second type of tourist, international residential tourists (IRTs). This is a segment that is experiencing significant growth, especially in some destinations, as is the case of traditional tourist destinations in southern Europe. This is reflected by the high numbers reached in cases like Spain, which is second after US in number of residential tourists worldwide and ahead from countries like France, Germany, Italy, or Greece (Taltavull \& Ramón, 2005).

The development and consolidation of this form of tourism implies a strong impact on the area where it takes place (Casado-Díaz, 1999), as well as on its economy, given that communities spring up formed by individuals of different nationalities, which are more or less homogenous, who become a semipermanent part of the consumer base in each tourist destination. The appearance of these new consumers in the area usually generates a debate on how to design strategies for this particular market. On the one hand, it can be considered that by spending long periods of time in the host community, they adapt sufficiently and it is not necessary to adopt commercial strategies that differ from those aimed at local residents. On the other hand, it may be thought that these residential tourists continue to maintain their own consumer habits and shopping motivations, different from those of the host community and therefore it is necessary to place emphasis on product ranges specifically designed for them.

Principally, it could be supposed that the IRTs, due to the fact that they are away from home and living side-by-side with the local population, could be subject to acculturation processes similar to those undergone by permanent emigrants (Berry, 2005). These processes could affect their shopping behaviors, as can be deduced from research such as that carried out by (Cornwell, WamwaraMbugua, \& Boller, 2008) in which acculturation has an influence on individuals when acting as consumers and provides keys towards improving the adaptation of the product range to some collectives who may have specific shopping behaviors and consumer needs (Peñaloza, 2010). However, recent research (De Juan-Vigaray, SarabiaSánchez, \& Garau-Vadell, 2013) has shown that the vast majority of IRTs have low levels of acculturation, although it is not clear what the ideal strategy is as far as this consumer segment is concerned. The available literature has not paid them sufficient attention, and despite a growing body of work on residential tourism there is still a limited number of works on IRTs relating to their shopping motivations. It is for this reason that this type of tourist and their shopping motivations has aroused our interest.

So, within this scope, this study focuses on a main research question: Is there a reliable evaluation tool that can be adapted to the IRT and, in that case, what are the shopping motives of this type of consumer? In order to answer this question, the following objectives have been set out: 1) to review existing literature related to measuring consumer shopping motivations; 2) to discuss and adapt a measurement scale in accordance with the specific characteristics of the IRTs; and 3) to corroborate their applicability in two top tourist destinations with a high number of IRTs. 
Theoretical Framework

\section{Conceptualizing the Residential Tourist}

The term "residential tourist" is a contradiction in itself because, if we refer to the main characteristic of residency, it should not be considered tourism (Torres Bernier, 2003). Although it is difficult to conceptualize the term residential tourism, it is generally accepted that it is that which involves people, normally families, who move to traditional tourist destinations, becoming linked to them through their property, where they stay for a period of less than 2 months at a time. In any event, the duration of said stay is usually longer than that of traditional tourists. The stay must take place in accommodation other than a hotel, generally bought, rented, borrowed, or timeshare property (Prado, 2004). More specifically, the bought property, according to the World Tourism Organization (UNWTO), refers to private property used as a second or recreational home or "owned dwelling," a second residence, in accordance with Eurostat's classification. It must be pointed out that the second home in the case of Spain (both for the surveys carried out relating to demand-Frontur and Familitur-and in the population and housing census) includes, as well as owned property, property that is rented for more than 6 months or dwellings belonging to family and friends.

In 1998 the European Commission defined "private tourism accommodation" as:

The remaining types of tourist accommodation that do not conform to the definition of "establishment." Each accommodation unit (room, dwelling) is independent and is occupied by tourists, usually by week or weekend, fortnight or month, or by its owners as a second or holiday home.

International residential tourism, as has already been pointed out, involves citizens of other nationalities who spend long stretches of time in the host country in any of the ways mentioned above.

\section{Consumer Shopping Motivations}

By and large, literature related to the study of consumer decision-making styles puts forwards three main points of view: 1) consumer characteristics approach (E. K. Sproles \& Sproles, 1990; G. B. Sproles \& Kendall, 1986); 2) psychographic/lifestyle approach (Wells, 1975); and 3) the consumer typology approach (Moschis, 1976). The connection between the three approaches is based on the fact that all consumers end up shopping while taking into account particular basic ways of making decisions - decision "motives" or "styles"-including rational buying, brand awareness, or taking into consideration, to a greater or lesser extent, the price, to name just a few basic variables.

The first approach focuses on the mental orientation of consumers when making their decisions. This means that affective as well as cognitive orientations in the consumer decision-making process are taken into account. This is based on the premise that decision-making styles may be determined by identifying general orientations towards shopping and shopping behavior (Sarabia-Sánchez \& De Juan-Vigaray, 2009). The psychographic approach, states that the activities, interests, and opinions of an individual may be highly effective in measuring their personality and predicting their shopping behavior (Wells, 1975). Finally, the third approach tries to define the aspects of the consumer motives and attitudes towards shopping by classifying them into a limited number of types each differing from the other (Shim, 1996). This standpoint appears to be very explanatory and its results are very useful for market researchers as well as for the managers of the retail companies where consumers do their shopping or for the public administration in the area in question, as they provide a qualitative instrument for classifying heterogeneous consumer decision-making motives.

To be precise, a shopper decision-making style consists of a mental orientation that determines the way in which decisions are made regarding the choice of products by the consumer, resulting in a relatively long-lasting consumer personality (G. B. Sproles \& Kendall, 1986). That is, the writers postulate that consumers adopt a shopping personality, which is relatively fixed and predictable, as a series of features that remain more or less stable throughout the course of each individual's development.

After carrying out the corresponding reliability and validity analyses, G. B. Sproles and Kendall (1986) identified and proposed the existence of eight 
shopping styles: 1) perfectionist or high-quality conscious consumer; 2) brand conscious consumer; 3) novelty and fashion conscious consumer; 4) recreational and hedonistic shopping conscious consumer; 5) price conscious consumer; 6) impulsive buyer; 7) consumer confused by overchoice; and 8) habitual, brand-loyal consumer.

Siu, Wang, Chang, and Hui (2001) review studies that focus on two objectives: 1) confirming the existence of styles of thought applied to the cognitions of consumer purchases and 2) checking that segmenting consumers into a significant number of groups according to their responses to shopping styles is viable as well as useful.

Research into shopping motivations (Park, Yu, \& Zhou, 2010) has delved into different motives, such as the motives of shopping close to home. Along these lines, it has been detected that these are instigators of consumer loyalty in local businesses (Noble, Griffith, \& Adjei, 2006). At the same time, different studies suggest that price-sensitive consumers are more likely to shop at different stores to benefit from the lowest prices (Popkowski-Leszczyc \& Timmermans, 1997). Within this scope, a study by Yavas (2003) identifies the price as a premise for the choice of establishment among a whole range of shopping motives.

As far as Wang, Chen, Chan, and Zheng (2000) are concerned, shoppers with strong hedonistic motives are not satisfied with the functional aspects of shopping and probably look for a more stimulating experience. Shopping for fun is associated with entertainment and this is achieved by visiting several shops and, if possible, with other consumers (Babin, Darden, \& Griffin, 1994). It is precisely hedonistic motives that are related with this type of reasons that are a delight for the senses and that take into account the entertainment factor when shopping, the atmosphere in the store, or the social interaction, as pointed out by Cardoso and Pinto (2010).

The research that used large-scale distribution as a context has identified the presence of behaviors that look for variety; therefore, when the options are within the consumer's reach, consumers regularly visit more than one supermarket or hypermarket for their shopping (Kahn \& McAlister, 1997).

Shopping motivations, due to their influence on shopping and consumption patterns, which in turn determine the consumer's behavior, remain relatively stable with the passing of time and, therefore, are relevant for market segmentation, as has been confirmed by numerous investigations in recent decades (Shim, 1996; Siu et al., 2001; G. B. Sproles \& Kendall, 1986). However, in the revised literature, works have not been detected that study the shopping behavior of IRTs in a different location than, generally, they are used to, nor have they studied the shopping motivations in the host destination in depth. It might be thought that by having different origins, customs, cultures, and/or subcultures to those in the host country, it is interesting to know these variables to be able to satisfy needs more effectively and gain further knowledge of this tourist niche.

\section{Measuring Shopping Styles}

Aware of the importance of identifying shopping styles for developing marketing strategies, different evaluation tools have been developed over the last few decades. The most classic and widely used evaluation tool is the so-called "Consumer Styles Inventory" (CSI) (E. K. Sproles \& Sproles, 1990). The CSI is based on the supposition that consumer decision making can be explained taking as a starting point eight decision-making factors that influence their behavior.

Although the CSI has been the preferred instrument of a multitude of academics in their research on shopping styles in different contexts, its generalization has not been left unquestioned. In spite of the eight-factor structure confirmed by the original study, several investigations have revealed indicators that question the fact that this model is able to represent an ideal solution, as some of the factors are not very reliable. Based on this evidence, different authors have proposed specific adaptations for certain countries (Shim, 1996). And authors like Noble et al. (2006) even propose an alternative evaluation tool that provides a theoretical foundation on the factors that lead to consumer loyalty to local stores, particularly taking into account the influence of shopping motives and consumer types.

The work of Noble et al. (2006) in particular suggests nine factors or shopping motivations. The first factor proposed was called information attainment and is conceived to be the motive for searching for external information related to product or service 
attributes. This first factor is measured using a method adapted by Dickerson and Gentry (1983) $(\alpha=$ 0.84 ). The second factor was called price comparison and is conceived to be the motive that all consumers have to compare the prices of products and services offered by different types of retailers and it is measured using the scale proposed by Eastlick and Feinberg (1999) $(\alpha=0.84)$. The third factor, uniqueness seeking, is conceived to be the desire to search for novelties and new products and is measured with a modified scale taken from Eastlick and Feinberg (1999) $(\alpha=0.75)$. The fourth factor, assortment seeking, is conceived to be the motive for having access to a wide range of products and is measured using a modified scale (the reliability of the original one has proven to be too low, like in some of the factors of E. K. Sproles \& Sproles, 1990) from Eastlick and Feinberg (1999) $(r=0.57, p<0.01)$. The fifth factor based on convenience seeking is conceived to be the motive for which consumers make an effort to save time when shopping and is measured using a modified version of the scale proposed by Eastlick and Feinberg (1999) $(\alpha=0.81)$. The sixth factor, social interaction or interrelation, is conceived to be a motivation related to the action of an individual and the response to that action, by one or more individuals during the shopping experience. This factor is measured using a three-item scale (Noble et al., 2006) $(\alpha=0.71)$. The seventh factor corresponds to the action of browsing by consumers and is conceived to be the motive behind looking at products for fun or entertainment, and is measured using a scale similar to that of Dawson, Bloch, and Ridgway (1990) $(\alpha=0.74)$. The factor relating to loyalty to local retailers is conceived to be the desire to buy products from local retailers and is measured using a three-item scale adapted by Blakney and Sekely (1994) $(\alpha=0.85)$ (see Table 1).

\section{International Residential Tourists and Their Shopping Motivations}

The pairing of "tourism and shopping" has been commonly analyzed in different works, such as those of Getz (1993) on tourist shopping villages (TSVs), recently updated by Murphy, Benckendorff, Moscardo, and Pearce (2011), or others like Kinley, Josiam, and Kim (2003), Oh, Cheng, Lehto, and O’Leary (2004), Saayman and Saayman (2012),
Wong and Wan (2013), and Yüksel (2007), but in all of these works the subjects of the study are traditional tourists.

Having reached this point in which we have reviewed the nature of residential tourists, especially that of IRTs, and consumer buying behavior, we are aware that existing literature up until now has not paid enough attention to studying the shopping motivations of an increasingly important segment, such as the one formed by IRTs.

\section{Methods}

The Development of a Specific Evaluation Tool for IRTs

Taking into account the difficulties detected in various studies when using the CSI in certain consumer structures and that the objective of this work is to study IRT shopping motivations, we came up with the idea of proposing an instrument that covers the reliable aspects of the instruments that have already been used and that is easy to manage and can be adapted to IRTs. In this way, upon proposing an evaluation tool, a decision was made to make the most of the high level of theoretical background in the Noble et al. (2006) scale and to adapt it to some of the specific characteristics of IRTs.

Along these lines, the proposed basis for measurement includes the 27 original items included in the Noble et al. (2006) scale, having made the following adaptations. In the case of the fourth factor, assortment seeking, another point has been added denominated shops must have a high variety of products to choose from. In this way, measurability is improved in relation with the original scale, which only contained two points. Likewise, to complete the shopping motivations we decided to include another factor that we call the time and effort that the IRTs are willing to dedicate to shopping in the stores. The fact that these consumers spend long stretches of time in the host country, but are not permanent residents, could influence their shopping behavior and could also be a variable that changes their behavior as consumers. In order to measure this last factor, a decision was made to operationalize it using the scale put forward by Baker, Parasuraman, Grewal, and Voss (2002), which contains four points related with the time that the 
consumer invests and the importance given to the time they take to do their shopping. This last variable appears as the last factor in Table 1.

Operatively, the measurement of all of the items that form the evaluation tool is carried out using 7-item Likert scales, on which the IRTs responded expressing their level of agreement with the statements given under each of the items. On said scales, the value 1 corresponded to I completely disagree with the statement and the value 7 corresponded to $I$ completely agree with the statement.

Finally, the evaluation tool that was devised specially to measure the shopping motivations of IRTs and is made up of 32 items can be seen in Table 1.

Table 1

IRT Shopping Motives

\begin{tabular}{|c|c|}
\hline Factors/Items & Description of the Item \\
\hline \multicolumn{2}{|c|}{ 1. Information level ${ }^{\mathrm{a}}$} \\
\hline a1 & I often seek out information regarding which brand to buy \\
\hline $\mathrm{a} 2$ & $\begin{array}{l}\text { I spend a lot of time looking for information about products and brands before I make } \\
\text { a purchase }\end{array}$ \\
\hline a3 & I like to have a great deal of information before I buy/anything \\
\hline a4 & I usually seek out product information before making a purchase \\
\hline \multicolumn{2}{|c|}{ 2. Price comparison ${ }^{\mathrm{a}}$} \\
\hline b1 & I often compare product prices across retailers to get the lowest price \\
\hline b2 & I usually find myself price comparison shopping \\
\hline b3 & $\begin{array}{l}\text { I often find myself looking for the exact same product at different outlets to find the } \\
\text { lowest price }\end{array}$ \\
\hline \multicolumn{2}{|l|}{ 3. Uniqueness ${ }^{\mathrm{a}}$} \\
\hline c1 & I enjoy searching for novel items to purchase \\
\hline c2 & When I shop I enjoy finding new and different styles \\
\hline c3 & I usually find myself looking for unique products to purchase \\
\hline \multicolumn{2}{|r|}{ 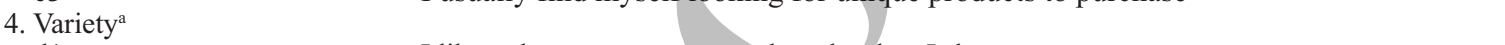 } \\
\hline d1 & I like to have access to many brands when I shop \\
\hline d2 & I like to have access to a wide selection of products when I shop \\
\hline d3 & Any shop must have a large variety of products to choose from \\
\hline \multicolumn{2}{|c|}{ 5. Convenience ${ }^{\mathrm{a}}$} \\
\hline e1 & When I shop, I want to find what I'm looking for in the least amount of time \\
\hline e2 & I want to expend little effort when I shop \\
\hline e3 & I want to shop in the least amount of time \\
\hline \multicolumn{2}{|c|}{ 6. Social interaction ${ }^{\mathrm{a}}$} \\
\hline f1 & I enjoy watching other people when I go shopping \\
\hline f2 & I enjoy interacting with others when I am shopping \\
\hline f3 & I miss the experience of interacting with people when shopping through an in-home method \\
\hline \multicolumn{2}{|l|}{ 7. Browsing ${ }^{\mathrm{a}}$} \\
\hline g1 & $\begin{array}{l}\text { I often visit shopping malls or markets just for something to do, rather than to buy } \\
\text { something specific }\end{array}$ \\
\hline g2 & I enjoy browsing for things in a store even if I cannot buy them yet \\
\hline g3 & In-store shopping is generally a lot of fun for me \\
\hline \multicolumn{2}{|c|}{ 8. Loyalty to local retailers ${ }^{\mathrm{a}}$} \\
\hline h1 & I shop locally to support local merchants and business districts \\
\hline h2 & I owe it to my community to shop at local stores \\
\hline h3 & I am loyal to my local shopping area \\
\hline \multicolumn{2}{|c|}{ 9. Loyalty posttest $\mathrm{t}^{\mathrm{a}}$} \\
\hline i1 & I shop locally to support locally owned and operated merchants \\
\hline $\mathrm{i} 2$ & I owe it to my community to shop at locally owned and operated merchants \\
\hline i3 & I am loyal to locally owned and operated merchants \\
\hline \multicolumn{2}{|c|}{ 10. Effort-time $\mathrm{b}^{\mathrm{b}}$} \\
\hline $\mathrm{j} 1$ & I shop locally to support locally owned and operated merchants \\
\hline $\mathrm{j} 2$ & I really don't give my purchases much thought or care \\
\hline $\mathrm{j} 3$ & I am loyal to locally owned and operated merchants \\
\hline j4 & I spend little time deciding on the products I buy \\
\hline
\end{tabular}

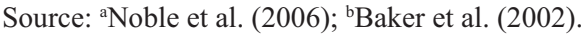




\section{Participants}

A total of 400 questionnaires were completed (200 in each tourist destination), with quotas set for country of origin, age, and sex. Table 2 shows the sample distribution. Finally, in the surveys that were filled out correctly, but a few missing answers were detected, a decision was made to replace the missing values with the average.

In order to validate the evaluation tool, firstly a factorial analysis with Varimax rotation was applied. Apart from the items included in each of the main factors obtained, each of the underlying dimensions (or factors) was named.

\section{Procedure}

In order to verify the effectiveness of the evaluation tool, the scale was tested in Spain, more specifically in the tourist destinations with the greatest concentrations of IRTs: Alicante and Majorca. Spain seemed to be a particularly appropriate choice, because it has the second highest number of IRTs after the US and, as was pointed out above, in Europe it is ahead of France, Germany, Italy, and Greece (Taltavull \& Ramón, 2005). In 2010 there were 1.9 million holiday homes belonging to citizens who were not resident in Spain. Back in 2001 the total amount of spending by residential tourists was 40,000 million Euros $(36.7 \%$ of the total foreign tourist expenditure) (SEGITTUR, 2011). These figures make IRTs a relevant segment for companies offering their products and services at tourist destinations and bring about the dilemma of whether or

Table 2

Sample Used in the Study $(N=400)$

\begin{tabular}{lc}
\hline Variables & Sample \\
\hline Age & \\
$25-39$ & $110(27.5 \%)$ \\
$40-59$ & $180(45.0 \%)$ \\
$60+$ & $110(27.5 \%)$ \\
Sex & \\
$\quad$ Male & $208(52.0 \%)$ \\
Female & $192(48.0 \%)$ \\
Destination & $188(47.1 \%)$ \\
$\quad$ Majorca & $212(53.0 \%)$ \\
Alicante & \\
Country of origin & $239(59.7 \%)$ \\
UK & $161(40.3 \%)$ \\
Germany & \\
\hline
\end{tabular}

not to aim different campaigns at them, considering them to be a segment with truly different behavior.

Similarly, the development of IRTs in Spain has led to significant concentrations, especially of German, British, or Norwegian communities, which in certain situations amount to as much as $40 \%$ of the inhabitants of some towns (Instituto Nacional de Estadística [INE], 2013). Finally, Spain seems to be a suitable place to test the scale due to the fact that it is a multicultural Western country with a Mediterranean lifestyle, open and different from that in other European countries where the IRTs come from.

The Spanish destinations chosen to carry out the research were Alicante and Majorca. Majorca is one of the top tourist destinations in the Mediterranean and received more than 9 million foreign tourists in 2010; Alicante is the second main host region for international tourists, with over 5.7 million visitors (Instituto de Estudios Turísticos [IET], 2011). Both destinations are the areas with the highest percentage of foreign inhabitants in Spain, with $21.69 \%$ (242,000 IRTs) and $24.15 \%$ (466,000 IRTs), respectively. Of these IRTs 130,000 and 293,000, respectively, come from the European Union, which is the main place of origin for tourists for both destinations (INE, 2013). In Majorca, the biggest IRT community is German, while in Alicante it is British, although both nationalities are common in both destinations.

In order to carry out the fieldwork, the services of a market research company were hired in each tourist destination and respondents were contacted using the "random route" method. Interviews were conducted on different days of the week, in the respondent's home or in other places frequently visited by the IRT, although supermarkets, cafés, and bars were avoided so that the responses would not be biased in relation with the type of consumption.

\section{Results}

The results of the analysis are shown in Table 3 and indicate the existence of seven main principles that explain $70.14 \%$ of the total variance. The underlying dimensions (or factors) were given the following denominations: shopping nearby, time saving, information available, fun/entertainment, good price seeking, and novelty seeking.

The first factor could be called shopping in the local vicinity. This is formed by items related to 
shopping in small stores close to the place of residence and in local businesses. As is shown in Table 3 , the items with high loadings coincide exactly with those included in theoretical dimensions 8: Loyalty to local retailers and 9: Loyalty posttest of the evaluation tool used.

The second factor is called time saving. It is made up of items relating to the consumer's desire to find what they are looking for in the shortest time possible in a speedy shopping process. As can be observed in Table 3, the items with high loadings coincide exactly with those included in theoretical dimensions 5: Convenience seeking and 10: Efforttime of the evaluation tool used.

The third factor could be designated information attainment. This factor is made up of items relating to the availability of information on the brand, products, etc. The items with high loading in this factor coincide exactly with those included in theoretical dimension 1: Information level.

The fourth factor could be called shopping for fun/entertainment, as it is formed by items related to the fun experienced in the shopping process and social interaction with other consumers. As can be seen in Table 3, the items with high loading coincide exactly with those included in theoretical dimensions 6: Social interaction/interrelation and 7: Browsing included in the proposed evaluation tool.

The fifth factor could be designated assortment variety, given that it is made up of items relating to the great variety of brands, products, etc. The items with high loading in this factor coincide exactly with those included in theoretical dimension 4: Variety seeking.

The sixth factor could be denominated good price seeking, being composed of items related to price comparison and the search for the lowest prices. The items with high loading in this factor coincide exactly with those included in theoretical dimension 2: Price comparison.

Finally, the last factor made clear by the factorial analysis could be denominated uniqueness seeking, as it is formed by items related to the search for innovative products, new, different, and unique styles. The items with high loading in this factor coincide exactly with those included in dimension 3: Uniqueness seeking of our evaluation tool.

Once the underlying factors had been revealed and with the aim of measuring the internal consistency of the different factors obtained, Cronbach's alpha was calculated for each dimension regarding the total sample, and the two subsamples $(N=200)$ corresponding with the two considered destinations. As can be observed in Table 3, said coefficient is in all factors over 0.8 for the total sample and the comparison, meaning that it is possible to confirm the internal consistency of the measurement made for each of the factors identified. The split sample strategy indicates that the comparison between the two subsamples showed no significant differences. These empirical evidences support the stability of the internal consistency of the factors.

Upon revising the scale proposed by Noble et al. (2006), which puts forward the nine factors, plus a new dimension that the authors proposed related to the time and effort required for shopping, and comparing it with the results obtained, a reduction in the number of dimensions can be observed from the 10 dimensions put forward initially down to 7. Although a priori this reduction could make us suspect a loss of validity in the proposed evaluation tool, a detailed study of the formation of the new dimensions has allowed us to confirm that the results obtained do not significantly affect the general logic explained by these authors. In fact, the dimensions that have "disappeared" have not really disappeared, but have fused to always give a broader dimension formed by the two previous dimensions.

In accordance with the explanation above, the theoretical dimensions 8: Loyalty to local retailers and 9: Loyalty posttest, which had been proposed independently in the evaluation tool, appear "fused together" in the results. That is, they form a single dimension denominated shopping in the local vicinity, which is highly relevant to the study of the IRT segment and therefore cannot be considered to be incoherent results. On the contrary, it seems reasonable to assume that all of the items of loyalty/ fidelity are loaded under the same factor (see the similarity of items h1, h2, h3, i1, i2, i3 in Table 1).

Finally, in the rest of the factors obtained, there is a practical coincidence between the factors proposed in the evaluation tool and the results achieved.

\section{Conclusions and Future Research}

From the results obtained, the applicability of the theoretical foundations for classifying shopping 
Table 3

Shopping motivation factors

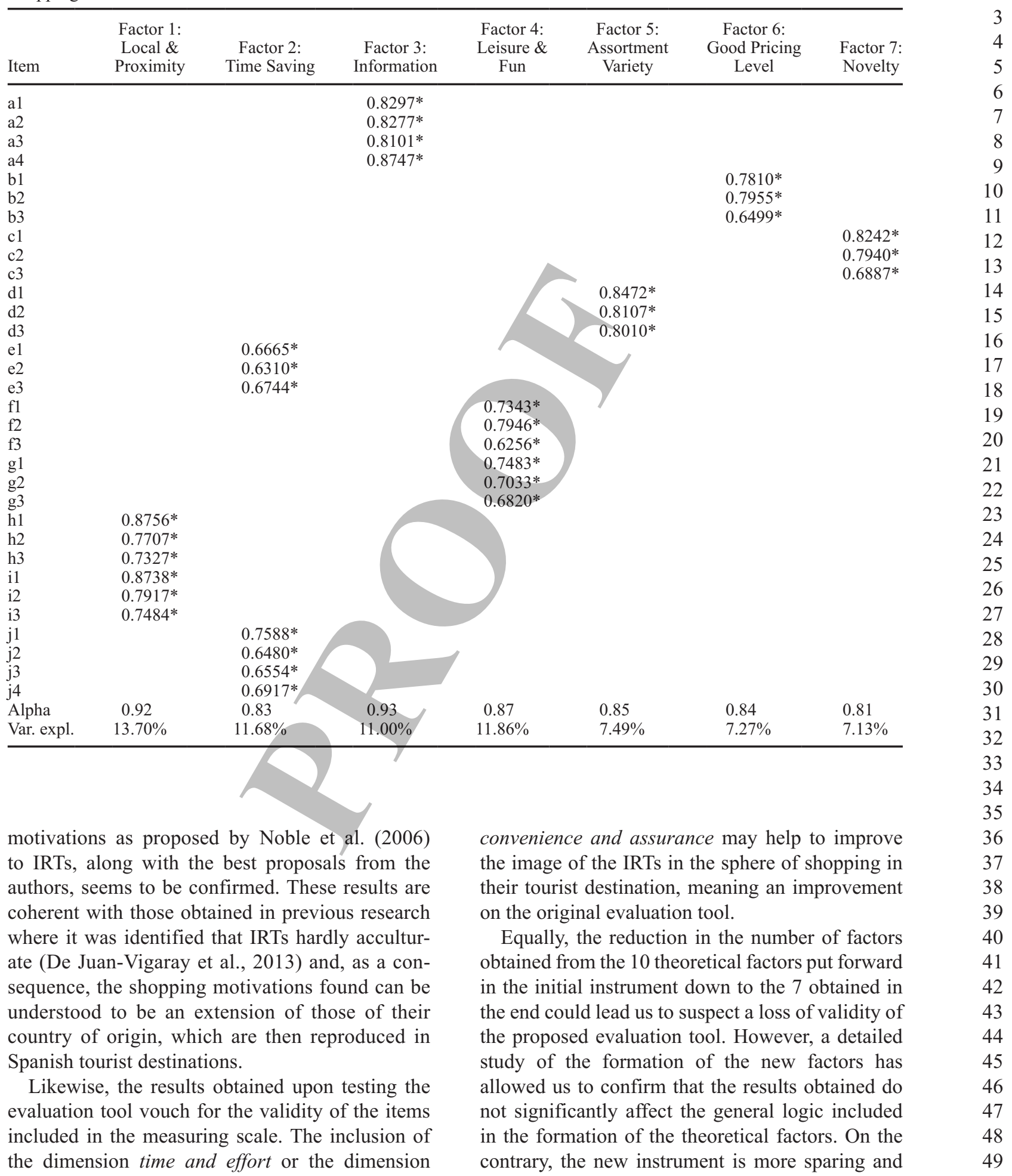


operational than the previous one and does not lose validity in its new format.

For tourist resort managers, as well as for retailers in the area, having access to a valid motivation measurement scale may be of great help. In this way, they can segment the IRTs in accordance with their shopping motivations and they will have a broader knowledge of the market and how it is formed. Knowing these motivations, it will be easier to implement marketing policies aimed at improving the planning of commercial areas, and will also help them to adapt their product range and communication to the segments that are of most interest to their companies and destinations.

Moreover, having an evaluation tool to confirm IRT shopping motivations implies significant progress in knowledge of consumer behavior in a very particular niche market. The IRT segment has been subject to constant growth and although this segment has slowed down somewhat recently, it is still very much existent in many of the traditional tourist destinations and the forecast is that it will grow again in the not too distant future. Furthermore, it is also suggested that shopping motivations could be included in a general model about traveling motivations. Furthermore, it is also suggested that shopping motivations could be included in a general model about traveling motivations. The comparison between residents and IRTs could be also a remarkable theoretical and empirical implication for future researchers - for instance, considering culture assimilation instead of acculturation.

As in all research work, we are aware of the existence of certain limitations. On the one hand, this is due to only having worked with two nationalities in two destinations. On the other hand, it is due to the difficulties encountered upon gathering different information from different types of IRTs, those on summer holidays or sporadic trips, semipermanent residents, etc. Finally, we believe that the quality of the measurement tool would probably increase if external validation, including criterion validity evidences, could be conducted in future development of this research.

Future lines of investigation will aim to define the consumer segments derived from these shopping motivations and to extend the application of the evaluation tool to other tourist destinations with different IRT nationalities, cultures, and subcultures.

\section{Acknowledgment}

The authors would like to express their thanks for the financial support received under the MCYTFEDER Research Project, grant SEJ-2006-08342/ ECON.

\section{References}

Alegre, J., \& Cladera, M. (2006). Repeat visitation in mature sun and sand holiday destinations. Journal of Travel Research, 44(3), 288-297. doi: 10.1177/0047287505279005

Babin, B. J., Darden, W. R., \& Griffin, M. (1994). Work and/or fun: Measuring hedonic and utilitarian shopping value. Journal of Consumer Research, 20, 644-656. doi: $10.1086 / 209376$

Baker, J., Parasuraman, A., Grewal, D., \& Voss, G. B. (2002). The influence of multiple store environment cues on perceived merchandise value and patronage intentions. Journal of Marketing, 66, 120-141. doi: http://dx.doi. org/10.1509/jmkg.66.2.120.18470

Berry, J. W. (2005). Acculturation: Living successfully in two cultures. International Journal of Intercultural Relations, 29, 697-712.

Blakney, V. L., \& Sekely, W. (1994). Retail attributes: Influence on shopping mode choice behavior. Journal of Managerial Issues, 6, 1.

Cardoso, P. R., \& Pinto, S. C. (2010). Hedonic and utilitarian shopping motivations among Portuguese young adult consumers. International Journal of Retail \& Distribution Management, 38(7), 538-558. doi: 10.1108/ 09590551011052124

Casado-Díaz, M. A. (1999). Socio-demographic impacts of residential tourism: A case study of Torrevieja, Spain. International Journal of Tourism Research, 1(4), 223-237. doi: 10.1002/(SICI)1522-1970(199907/08)1:4<223::AIDJTR153>3.0.CO;2-A

European Commission. (1998). Decision by the Commission on December 9, 1998 regarding application procedures for the Council Directive on Tourism Statistics 95/97EC. Recommendations on Tourism Statistics (UNWTO), year 2000.

Cornwell, T. B., Wamwara-Mbugua, L. W., \& Boller, G. (2008). Triple acculturation: The role of African Americans in the consumer acculturation of Kenyan immigrants. Journal of Business Research, 61(2), 83-90. doi: org/10.1016/j.jbusres.2007.04.011

Dawson, S. Bloch, P. H., \& Ridgway, N. M. (1990). Shopping motives, emotional states, and retail outcomes. Journal of Retailing, 60, 408-427.

De Juan-Vigaray, M. D., Sarabia-Sánchez, F. J, \& GarauVadell, J. (2013). The acculturation of international residential tourists and their shopping behaviours. Tourism Management, 36, 115-118. doi: 10.1016/j.tourman.2012. 11.017

Dickerson, M. D, \& Gentry, J. W. (1983). Characteristics of adopters and non adopters of home computers. Journal of Consumer Research, 10, 225-235. doi: 10.1086/208961 
Eastlick, M. A., \& Feinberg, R. A. (1999). Shopping motives for mail catalog shopping. Journal of Business Research, 45(3), 281-290. doi: 10.1016/S0148-2963(97)00240-3

Getz, D. (1993). Tourist shopping villages: Development and planning strategies. Tourism Management, 14(1), 15-26. doi: 10.1016/0261-5177(93)90078-Y

Hawkes, E., \& Kwortnik, R. J. (2006). Connecting with the culture: A case study in sustainable tourism. Cornell Hotel and Restaurant Administration Quarterly, 47(4), 369-381. doi: 10.1177/0010880406289992

Instituto de Estudios Turísticos. (2011). Encuesta de movimientos turísticos en fronteras. (Survey on inland tourist movements). Spanish Ministry for Industry, Energy and Tourism.

Instituto Nacional de Estadística. (2013). Revision of the municipal census. 2011. Retrieved from http://www.ine.es

Kahn, B. E., \& McAlister, L. (1997). Grocery revolution: The new focus on the consumer. Boston, MA: Addison Wesley.

Kaftanoglu, B., \& Timothy, D. J. (2013). Return travel, assimilation, and cultural maintenance: An example of Turkish-Americans in Arizona. Tourism Analysis, 18(3), 273-284. doi: 10.3727/108354213X13673398610655

Kinley, T. R., Josiam, B., \& Kim, Y. (2003). Why and where tourists shop: Motivations of tourist-shoppers and their preferred shopping center attributes. Journal of Shopping Center Research, 9(1), 7-28.

Laesser, C., \& Zehrer, A. (2012). Tell me who you think you are and I tell you how you travel. Exploring the viability of market segmentation by means of travelers' stated personality: Insights from a mature market (Switzerland). Tourism Analysis, 17(3), 285-298. doi: 10.3727/108354 212X13412775927781

Moschis, G. P. (1976). Shopping orientations and consumer uses of information. Journal of Retailing, 52, 61-70.

Murphy, L., Benckendorff, P., Moscardo, P., \& Pearce, P. L. (2011). Tourist shopping villages: Forms and functions. New York: Routledge.

Noble, S. M., Griffith, D., \& Adjei, M. T. (2006). Drivers of local merchant loyalty: Understanding the influence of gender and value orientation. Journal of Retailing, 82(3), 177-188. doi: 10.1016/j.jretai.2006.05.002

Oh, J. Y.-J., Cheng, C. K., Lehto, X. Y., \& O'Leary, J. T. (2004). Predictors of tourists' shopping behaviour: Examination of socio-demographic characteristics and trip typologies. Journal of Vacation Marketing, 10(4), 308-319. doi: $10.1177 / 135676670401000403$

O'Reilly, K. (2007). Emerging tourism futures: Residential tourism and its implications. In C. Geoffroy \& R. Sibley (Eds.), Going abroad: Travel, tourism and migration. Crosscultural perspectives on mobility (pp. 144-157). Newcastle: Cambridge Scholars Publishing.

Park, J. E., Yu, J., \& Zhou, J. X. (2010). Consumer innovativeness and shopping styles. Journal of Consumer Marketing, 27(5), 437-446. doi: 10.1108/07363761011063330

Peñaloza, L. (2010). Consumer acculturation. In Wiley international encyclopedia of marketing. Part 3: Consumer behavior. Hoboken, NJ: John Wiley.
Popkowski-Leszczyc, P., \& Timmermans, H. (1997). Storeswitching behavior. Marketing Letters, 8(2), 193-204. doi: 10.1023/A:1007910503617

Prado. (2004). Turismo residencial: Su participación en el desarrollo empresarial y socioeconómico de la provincia. Documento del Patronato de Turismo de la Costa del Sol Málaga.

Saayman, M., \& Saayman, A. (2012). Shopping tourism or tourists shopping? A case study of South Africa's African tourism market. Tourism Economics, 18(6), 1313-1329.

Sarabia-Sánchez, F. J., \& De Juan-Vigaray, M. D. (2009). Los valores de los consumidores y el comportamiento de ir de compras. REIM (Revista Española De Investigación De Marketing)-ESIC, 13(1), 7-34.

SEGITTUR. (2011). Horizonte 2020 del turismo español. Documento Base. Retrieved from http://www.tourspain. es/es-es/VDE/Documentos\%20Vision\%20Destino $\% 20$ Espaa/Plan_Turismo_Espa\%C3\%B1ol_Horizonte_2020. pdf [4th July 2012]

Shim, S. (1996). Adolescent consumer decision-making styles: The consumer socialization perspective. Psychology and Marketing, 13(6), 547-569. doi: 10.1002/(SICI)15206793(199609)13:6<547::AID-MAR2>3.0.CO;2-8

Siu, N., Wang, C. L., Chang, L., \& Hui, A. (2001). Adapting consumer style inventory to Chinese consumers: A confirmatory factor analysis approach. Journal of International Consumer Marketing, 13(2), 29-47. doi: 10.1300/ J046v13n02 03

Sproles, E. K., \& Sproles, G. B. (1990). Consumer decisionmaking styles as a function of individual learning styles. Journal of Consumer Affairs, 24, 134-147. doi: 10.1111/ j.1745-6606.1990.tb00262.x

Sproles, G. B., \& Kendall, E. L. (1986). A methodology for profiling consumer decision-making styles. The Journal of Consumer Affairs, 20, 267-279. doi: 10.1111/j.17456606.1986.tb00382.x

Taltavull, P., \& Ramón, A. B. (2005). Turismo y vivienda. Economistas, 103, 66-80.

Torres Bernier, E. (2003). El turismo residenciado y sus efectos en los destinos turísticos. Estudios Turísticos, 155, 45.

Wang, C. L., Chen, Z. X., Chan, A. K. K., \& Zheng, Z. C. (2000). The influence of hedonic value on consumer behaviours: An empirical investigation in China. Journal of Global Marketing, 14(1/2), 169-186. doi: 10.1300/J042v14n01_09

Wells, W. D. (Ed.). (1975). Life style and psychographics. Chicago, IL: American Marketing Association.

Wong, I. A., \& Wan, Y. K. P. (2013). A systematic approach to scale development in tourist shopping satisfaction: Linking destination attributes and shopping experience. Journal of Travel Research, 52(1), 29-41. doi: 10.1177/ 0047287512457263

Yavas, U. (2003). A multi-attribute approach to understanding shopper segments. International Journal of Retail \& Distribution Management, 31(11), 541-548. doi: 10.1108/09590550310503276

Yüksel, A. (2007). Tourist shopping habitat: Effects on emotions, shopping value and behaviors. Tourism Management, 28(1), 58-69. doi: 10.1016/j.tourman.2005.07.017

\section{1}




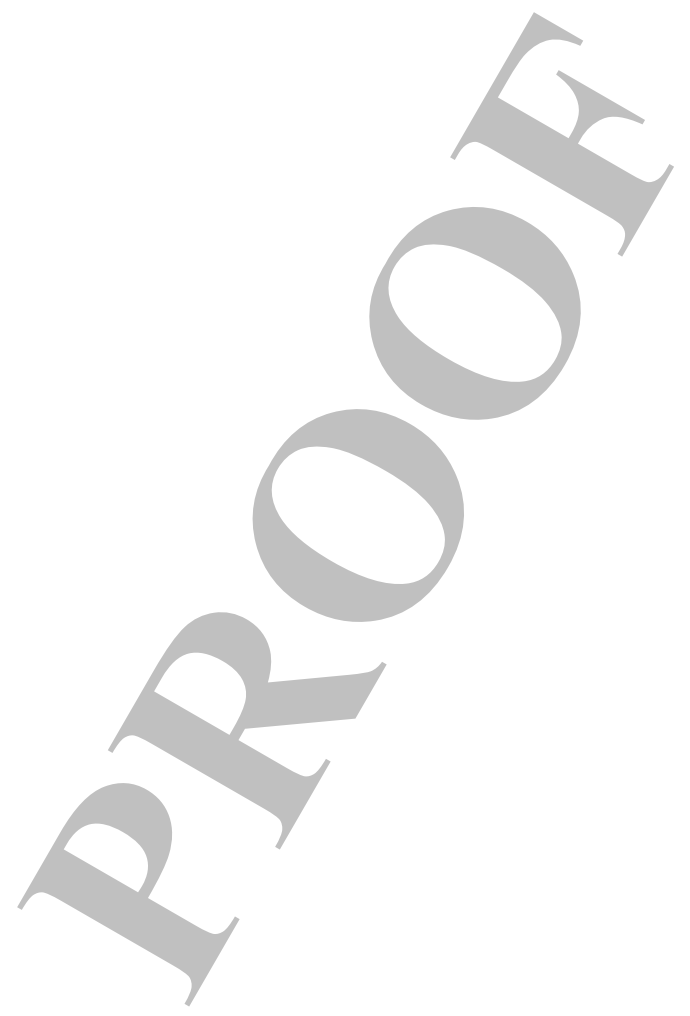

